\title{
The Sub Acute Toxicity Evaluation of Stereospermum kunthianum Aqueous Methanolic Stem Bark Extract
}

\author{
Maxwell Osaronowen Egua ${ }^{1 *}$, Ode Julius Okwoche ${ }^{2}$, Florence Chimezie Nwinyi², \\ Onakpa Michael Monday², Akande Motunrayo Ganiyat ${ }^{2}$, Samson Eneojo Abalaka ${ }^{3}$, \\ Mikail Hudu Garba ${ }^{2}$, Akumka David Dezi², Adamu Mohammed² \\ ${ }^{1}$ Department of Pharmacology and Therapeutics, College of Health Sciences, University of Abuja, Abuja, Nigeria \\ ${ }^{2}$ Department of Pharmacology and Toxicology, Faculty of Veterinary Medicine, University of Abuja, Abuja, Nigeria \\ ${ }^{3}$ Department of Veterinary Pathology, Faculty of Veterinary Medicine, University of Abuja, Abuja, Nigeria \\ Email: ^egua.osaronowen@uniabuja.edu.ng
}

How to cite this paper: Egua, M.O., Okwoche, O.J., Nwinyi, F.C., Monday, O.M., Ganiyat, A.M., Abalaka, S.E., Garba, M.H., Dezi, A.D. and Mohammed, A. (2021) The Sub Acute Toxicity Evaluation of Stereospermum kunthianum Aqueous Methanolic Stem Bark Extract. Journal of Biosciences and Medicines, 9, 71-86.

https://doi.org/10.4236/jbm.2021.912006

Received: October 22, 2021

Accepted: December 3, 2021

Published: December 6, 2021

Copyright $\odot 2021$ by author(s) and Scientific Research Publishing Inc. This work is licensed under the Creative Commons Attribution-NonCommercial International License (CC BY-NC 4.0). http://creativecommons.org/licenses/by-nc/4.0/

\begin{abstract}
Stereospermum kunthianum (Bignoniaceae) is a plant widely used for health benefits. A safety profile evaluation (acute toxicity study) of the plant extract is critical, in a step to the systematic pharmacognostic study of this plant. Thirty-two (32) rats were randomly selected and divided into four groups labelled 1 to 4 with the initial weights of the rats recorded. The animals in group 1 served as control and were administered distilled water, while those in Groups 2, 3 and 4 received 100, 200, and $400 \mathrm{mg} / \mathrm{kg}$ respectively, of the Stereospermum kunthianum aqueous methanolic stem bark extract daily. The results indicated no deaths, no observable clinical signs of toxicity, no obvious stress or changes in physical appearance or behaviour in the rats. This general picture of safety is further supported by the multiple comparison post hoc test (Turkey's) of, the organs weights, the renal (electrolyte, urea and creatinine), the haematological parameters (RBC, HB, PCV, MCV, MCH, $\mathrm{MCHC}$, and Platelet), and the hepatic enzymes (AST and ALT), that all showed the control group to be insignificantly different from the extract treated groups. In conclusion, the extract was deduced to be safe on oral administration for 28 days and it also showed a hepatoprotective quality.
\end{abstract}

\section{Keywords}

Stereospermum kunthianum, Sub Acute, Toxicity, Control, Treatment Group

\section{Introduction}

Stereospermum kunthianum (Bignoniaceae) is a plant widely used for numerous 
health benefits and various ailments have been treated using different parts of the plant in Africa [1]. The plant is a deciduous tree (3 - 15 metres tall) found in Tropical countries of Africa, often grown as an ornamental plant [2] and found also in some Asian countries. A decoction of the roots was acknowledged in ethno-botanical survey among the Igede people in the middle belt of Nigeria to be effective against diabetes [3], the use is being investigated by our research team, and for which the sub acute toxicity study is demanded as part of the pharmacognostic evaluation of the plant. The other parts of the plant that is the pods were used in the treatment of cough, ulcers, leprosy, skin eruptions and venereal diseases [4], the leaf infusion was employed for washing wounds, while the macerated leaves were used to treat asthenia and exhaustion and the bark served as a haemostatic (in treating wounds). Some other uses included the stem decoction as recipe for bronchitis, pneumonia and cough; the roots and leaves were used in the treatment of venereal diseases, respiratory ailments and gastritis [5]; while the aqueous stem bark extract was documented as protective against generalized seizures in pentylenetetrazole and electro-convulsive models in rodents [6].

A safety profile evaluation (acute toxicity study) of the extract is critical and had been undertaken and found to be greater than $5000 \mathrm{mg} / \mathrm{kg}$ in rats [7] as a step to the systematic pharmacognostic study of this plant. In furtherance of the pharmacognostic study, the in vivo sub acute toxicity study is being evaluated in rats (present study) because of their biological similarity to humans and susceptibility to many of the same health problems and therefore the possibility of extrapolations.

\section{Materials and Methods}

\subsection{Plant Collection and Preparation}

Fresh stem bark of $S$. kunthianum was collected from Suleja, Abuja, Nigeria in December 2017. The plant material was identified by a taxonomist, and assigned a voucher number (NIPRID H. 7072) was deposited in the National Institute for Pharmaceutical Research and Development (NIPRID), Abuja herbarium for future reference. The plant sample was air-dried and reduced to coarse particles by using a mortar and pestle before being pulverized into fine particles by using a laboratory hammer mill. The powder was exhaustively extracted in $80 \%$ methanol by double maceration with agitation on a shaker for $24 \mathrm{~h}$. The extract was then filtered using Whatman size 1 filter paper and the filtrate concentrated at $40^{\circ} \mathrm{C}$ using rotary evaporator (Rotavapor R 210, Buchi, Switzerland). The extract was subsequently dried over a water bath, and was stored in a refrigerator at $4^{\circ} \mathrm{C}$ for further use in the studies.

\subsection{Animals}

Matured healthy Wistar rats (150 - $220 \mathrm{~g})$ of both sexes were obtained from the animal holding unit of the National Institute for Pharmaceutical Research and 
Development (NIPRD) Abuja, Nigeria and used for the studies. The animals were housed in stainless steel cages at room temperature $\left(27^{\circ} \mathrm{C}-28^{\circ} \mathrm{C}\right)$ and under a $12 \mathrm{~h}$ light/dark cycle (lights on 07:00-19:00) daily for a period of 2 weeks prior to the commencement of the experiments for acclimatization in the Laboratory Animal Unit of the Faculty of Veterinary Medicine, University of Abuja, Nigeria. Standard commercial feed (Grand Cereals Ltd ${ }^{\circledR}$. Jos, Nigeria) and portable water were provided ad libitum. All efforts were made to minimize animal suffering and reduce the number of animals used. The laboratory animals were used in accordance with laboratory practice regulation and the principle of humane laboratory animal care as documented by Zimmermann [8].

\subsection{Instrument, Consumables and Reagents}

Analytical grade chemicals, freshly prepared solutions and standard drugs were used for the experiments. Methanol was obtained from Riedel-de Haen, Germany; tetraoxosulphate (VI) acid, Giemsa stain (Sigma, St. Louis, Missouri, USA), and $10 \%$ formal saline. Chloroform was obtained from Sigma Aldrich, USA, and used in the experiments. Analytical weighing balance (Metler) Switzerland, Toploading Balance (Ohaus scale) England, Table Centrifuge (Heraeus Christ) Germany, Rotary Evaporator (Rotavapor R 210, Buchi,) Switzerland, and Distilled water.

\subsection{Sub-Acute Toxicity}

Thirty-two (32) rats were randomly selected and divided into four groups labelled 1 to 4 with the initial weights of the rats recorded. The animals in group 1 served as control and were administered distilled water, while those in Groups 2, 3 and 4 received 100, 200, and $400 \mathrm{mg} / \mathrm{kg}$ respectively, of the Stereospermum kunthianum aqueous methanolic stem bark extract daily. The administration of the extract was oral, by feeding tube for 28 days. A stock solution of the extract was made per group and uniformly mixed/stirred before the exact dose were drown with the help of the weight of the rats and administered by gastric lavage. The male rats were separated from the female rats in each of the groups. The feed and water consumption of the rats were observed daily. The Organization for Economic Co-operation and Development (OECD) Guideline 407 for the sub-acute oral toxicity test [9] was followed with some modifications. Twelve hours (12 hrs) prior to the commencement of the experiment, all the rats (all groups) were fasted but allowed free access to water. On the last day of the experiment (29th day), blood samples were collected following chloroform anaesthesia (in a jar containing cotton wool saturated with chloroform.) through cardiac puncture. Blood samples were collected for biochemical analysis in non heparinised bottles and that for haematological studies in EDTA bottles. The lungs, liver, heart, spleen and kidney were collected, weighed, and stored in 10\% formalin, for histopathological study. The experimental procedure adopted standard methods [9] [10] [11].

The research was approved by the University of Abuja research ethics com- 
mittee on animal use (and assigned number UAECAU/2018/002) for the team.

\subsection{Haematological Studies}

The red blood cell count (RBC), haemoglobin concentration (Hb), packed cell volume (PCV), mean corpuscular volume (MCV), mean corpuscular hemoglobin $(\mathrm{MCH})$, mean corpuscular hemoglobin concentration (MCHC) and white blood cell count (WBC) were the evaluated hematological parameters determined from the blood samples collected in EDTA bottles using a MeCan three parts differential Haematology auto-analyzer (MCL-3800 MeCan Medical China).

\subsection{Biochemical Studies}

The blood samples collected in non heparinised bottles were centrifuged, using centrifuge model 8000D Germany, for 5 minutes and the sera were collected in plain test tubes and stored in the deep freezer at $-17^{\circ} \mathrm{C}$ until required for the assessment of renal function; determination of 1) Urea (Randox kit, Urease-Bertholot method) 2) Creatinine [12] 3) Sodium and Potassium (flame photometry method) 4) Biocarbonate (Slyke titration method) and the assessment of liver function i) Alanine amino transferase (ALT) (The Randox kit) ii) Aspartate amino transferase (AST) (Randox kit) [12].

\subsection{Gross and Histopathological Studies}

A day after the last dose of the drug administration, the animals were sacrificed after general anesthesia, with chloroform, then, the lungs, liver, heart, spleen, and kidney of each rat were removed, grossly examined, and weighed. The tissues were fixed in formalin-acetic acid fixative, embedded in paraffin wax, sectioned, and stained with Haematoxylin and Eosin for histological examination.

\subsection{Statistical Analysis}

The SPSS statistical software (version 20) USA was used for the analysis and results were expressed as Mean \pm SEM (standard error of the mean). One-way analysis of variance (ANOVA) was employed in the data analysis and the Tukey test was used for the post hoc analyses. The significance level was set at $\mathrm{p} \leq 0.05$.

\section{Results}

\subsection{Adverse Effects and Mortality of the Crude Extract}

There were no deaths recorded over the 28 days study period. Also there were no observable clinical signs of toxicity, stress or changes in physical appearance or behaviour in the rats within the groups.

\subsection{Feed and Water Consumption of the Animals}

The effect of Stereospermum kunthianum aqueous methanolic stem bark extract on feed intake is showed in Figure 1.

One-way analysis of variance (ANOVA) between groups and within groups for 


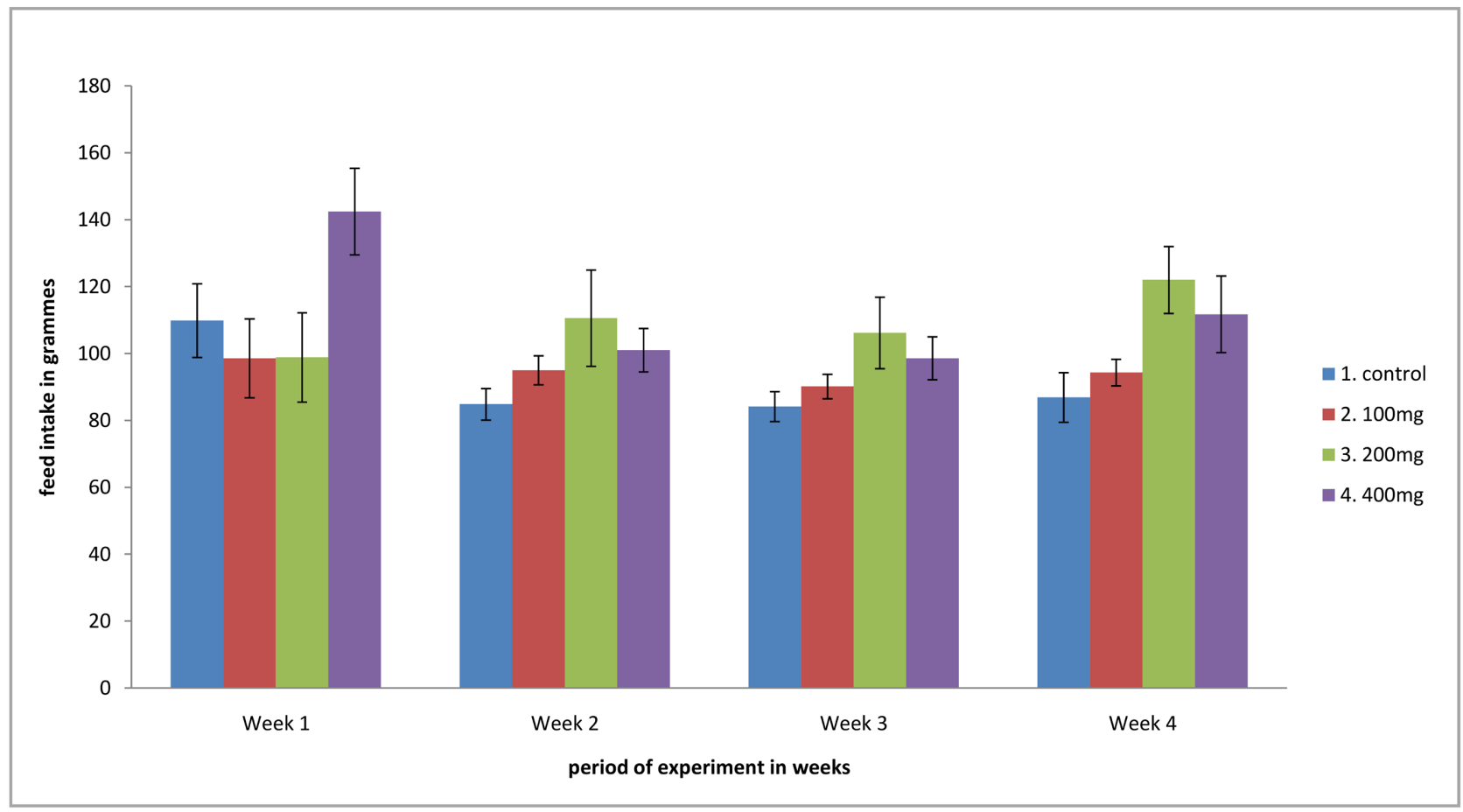

Figure 1. Effect of Stereospermum kunthianum aqueous methanolic stem bark extract on feed intake.

each week $(1-4)$ of the experiment indicated significant difference in the intake feeds on the $1^{\text {st }}(\mathrm{p} \leq 0.021)$ and $4^{\text {th }}(\mathrm{p} \leq 0.009)$ week. The multiple comparison post hoc tests (Turkey) showed the control was insignificantly different with the other groups in the intake feeds on the $1^{\text {st }}, 2^{\text {nd }}$ and $3^{\text {rd }}$ week but only significant with the group 3 (the $200 \mathrm{mg}$ extract administered) at the $4^{\text {th }}$ week of the experiment.

The effect of Stereospermum kunthianum aqueous methanolic stem bark extract on water intake is showed in Figure 2.

One-way analysis of variance (ANOVA) between groups and within groups for each week $(1-4)$ of the experiment indicated significant $(\mathrm{p} \leq 0.000)$ differences in the intake of water. The Turkey's multiple comparison post hoc test showed that the control was significantly different $(p \leq 0.013)$ with group 3 (the $200 \mathrm{mg} / \mathrm{kg}$ extract administered) in the intake of water on the first week of the experiment; groups 3 and 4 ( $\mathrm{p}<0.004$ and 0.017 respectively) on the $2^{\text {nd }}$ week; groups 3 and $4(\mathrm{p}<0.000$ and 0.000$)$ on the $3^{\text {rd }}$ week and only group $2(\mathrm{p}<0.05)$ on the $4^{\text {th }}$ week of the experiment.

\subsection{The Effect of Stereospermum kunthianum Aqueous Methanolic Stem Bark Extract on Hematological Indices of the Rats}

The effect of Stereospermum kunthianum aqueous methanolic stem bark extract on white blood cells and differential counts of rats is shown in Table 1 and Table 2. The one-way analysis of variance (ANOVA) between groups and within groups for the haematological parameters showed significance for the following only; RBC $\mathrm{p}<0.045, \mathrm{HB} p<0.024$ and PCV (pack cell volume) $\mathrm{p}<0.016$. While 


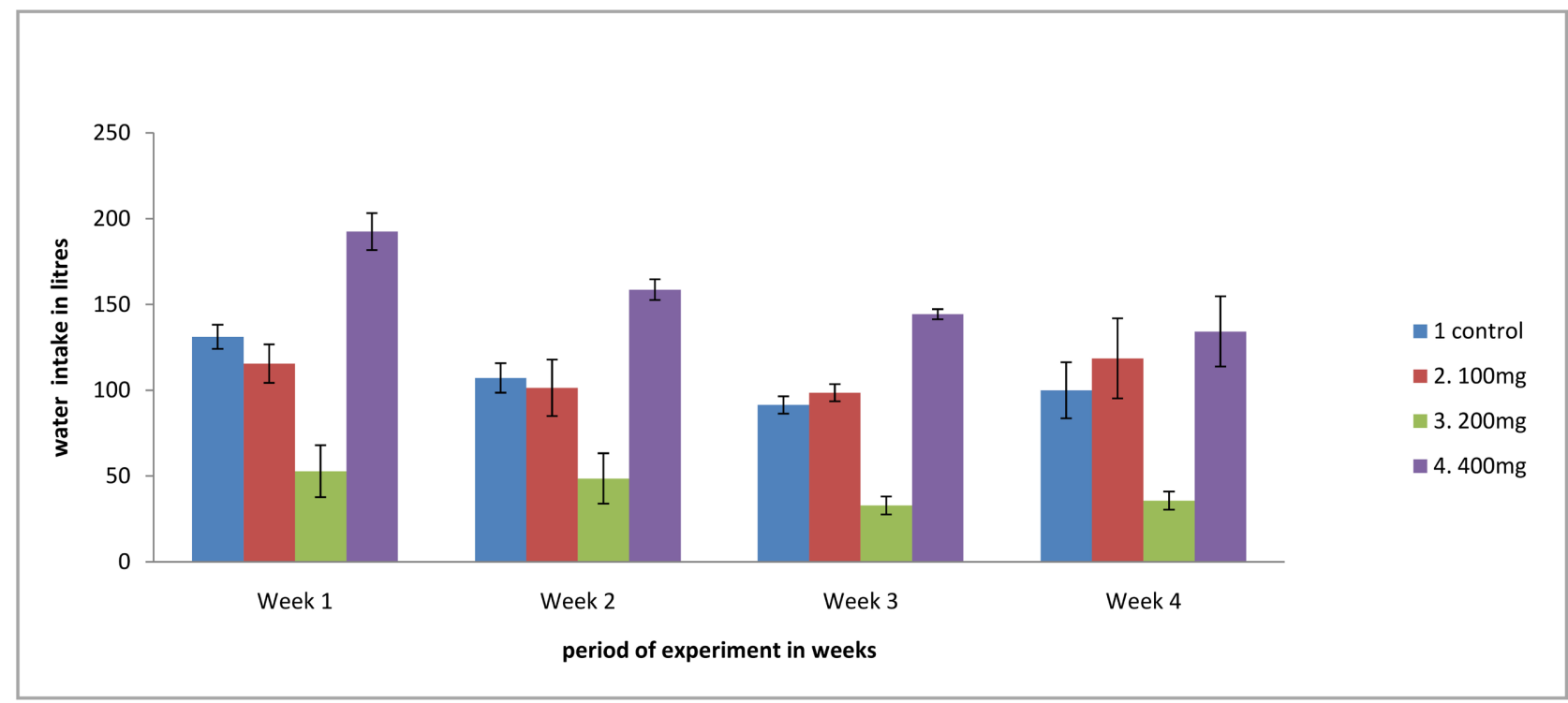

Figure 2. Effect of Stereospermum kunthianum aqueous methanolic stem bark extract on water intake.

Table 1. Effect of Stereospermum kunthianum aqueous methanolic stem bark extract on white blood cells and differential counts of rats.

\begin{tabular}{ccccccc}
\hline Group & WBC & Neutrophil & Lymphocytes & Monocytes & Eosinophil & Basophil \\
\hline 1. Control & $13.47 \pm 1.17$ & $17.00 \pm 3.61$ & $77.00 \pm 5.69$ & $5.00 \pm 1.73$ & $0.33 \pm 0.33$ & $0.33 \pm 0.33$ \\
$2.100 \mathrm{mg} / \mathrm{kg}$ & $12.00 \pm 3.17$ & $14.00 \pm 3.51$ & $82.00 \pm 6.51$ & $7.00 \pm 2.89$ & $1.00 \pm 1.00$ & $0.00 \pm 0.00$ \\
$3.200 \mathrm{mg} / \mathrm{kg}$ & $8.37 \pm 3.03$ & $22.33 \pm 5.04$ & $70.00 \pm 5.00$ & $6.33 \pm 0.88$ & $1.33 \pm 0.67$ & $0.00 \pm 0.00$ \\
$4.400 \mathrm{mg} / \mathrm{kg}$ & $14.93 \pm 1.66$ & $13.67 \pm 3.28$ & $79.67 \pm 2.33$ & $4.67 \pm 0.88$ & $1.67 \pm 0.33$ & $0.00 \pm 0.00$ \\
ANOVA & 0.175 & 0.474 & 0.387 & 0.825 & 0.281 & 0.463 \\
\hline
\end{tabular}

Table 2. Effect of Stereospermum kunthianum aqueous methanolic stem bark extract on Hematological indices of rats.

\begin{tabular}{cccccccc}
\hline Group & RBC & HB & PCV & MCV & MCH & MCHC & PLATELET \\
\hline 1. Control & $5.89 \pm 0.15$ & $13.47 \pm 0.35$ & $42.63 \pm 0.72$ & $72.50 \pm 1.64$ & $22.87 \pm 0.54$ & $31.53 \pm 0.32$ & $401.00 \pm 97.62$ \\
$\mathbf{2 . 1 0 0 ~} \mathrm{mg} / \mathrm{kg}$ & $6.00 \pm 0.52$ & $14.03 \pm 1.37$ & $45.53 \pm 4.44$ & $75.87 \pm 1.30$ & $23.33 \pm 0.59$ & $30.77 \pm 0.41$ & $878.00 \pm 386.3$ \\
$\mathbf{3 . 2 0 0 ~ \mathrm { mg } / \mathrm { kg }}$ & $4.02 \pm 0.98$ & $8.47 \pm 2.44$ & $28.33 \pm 6.97$ & $71.773 \pm 3.74$ & $20.57 \pm 0.93$ & $28.77 \pm 1.89$ & $371.33 \pm 87.31$ \\
$\mathbf{4 . 4 0 0 \mathrm { mg } / \mathrm { kg }}$ & $6.34 \pm 0.18$ & $14.50 \pm 0.32$ & $48.00 \pm 0.78$ & $75.80 \pm 1.45$ & $22.77 \pm 0.50$ & $30.07 \pm 0.22$ & $741.67 \pm 78.28$ \\
ANOVA & 0.045 & 0.024 & 0.016 & 0.55 & 0.184 & 0.545 & 0.362 \\
\hline
\end{tabular}

the multiple comparison post hoc test (Turkey's) showed the control was insignificantly different $(p>0.05)$ with the other groups $(2,3$, and 4$)$ in all the haematological parameters.

\subsection{The Effects of Stereospermum kunthianum Aqueous Methanolic Stem Bark Extract on the Kidney}

The Effects of Stereospermum kunthianum aqueous methanolic stem bark extract on renal (electrolyte, urea and creatinine) indices are shown in Figure 3. And the one-way analysis of variance between groups and within groups for the renal parameters showed $\mathrm{Na}^{+}, \mathrm{Cl}^{-}$and urea to have $\mathrm{p}$ values of $0.012,0.019$ and 
0.002 respectively. The Turkey's multiple comparison post hoc test showed the control group for all the parameter was insignificantly different $(p>0.05)$ compared to the other groups $(2,3$, and 4$)$ in all the renal parameters measured.

\subsection{The Effects of Stereospermum kunthianum Aqueous Methanolic Stem Bark Extract on the Liver}

The effects of Stereospermum kunthianum aqueous methanolic stem bark extract on two hepatic parameters are shown in Figure 4. The one-way analysis of variance between groups and within groups for the hepatic parameters was insignificant $p>0.05$. And the Turkey's multiple comparison post hoc test showed the control group for all the parameter was insignificantly different ( $p>0.05)$ compared to the other groups $(2,3$, and 4 ) for both parameters (AST and ALT).

\section{The Gross and Histopathological Organ Outcomes}

\subsection{The Organ Weights of Animals}

The effects of Stereospermum kunthianum aqueous methanolic stem bark extract on organ weights of rats (Figure 5) The ANOVA between groups and within groups for the organ weights indicated that only the kidney weights were significant $(\mathrm{p}<0.010)$. While the Turkey's multiple comparison post hoc test showed the control group organ weight in all the organs to be insignificantly different $(p>0.05)$ with the other groups $(2,3$, and 4$)$ organs weights.

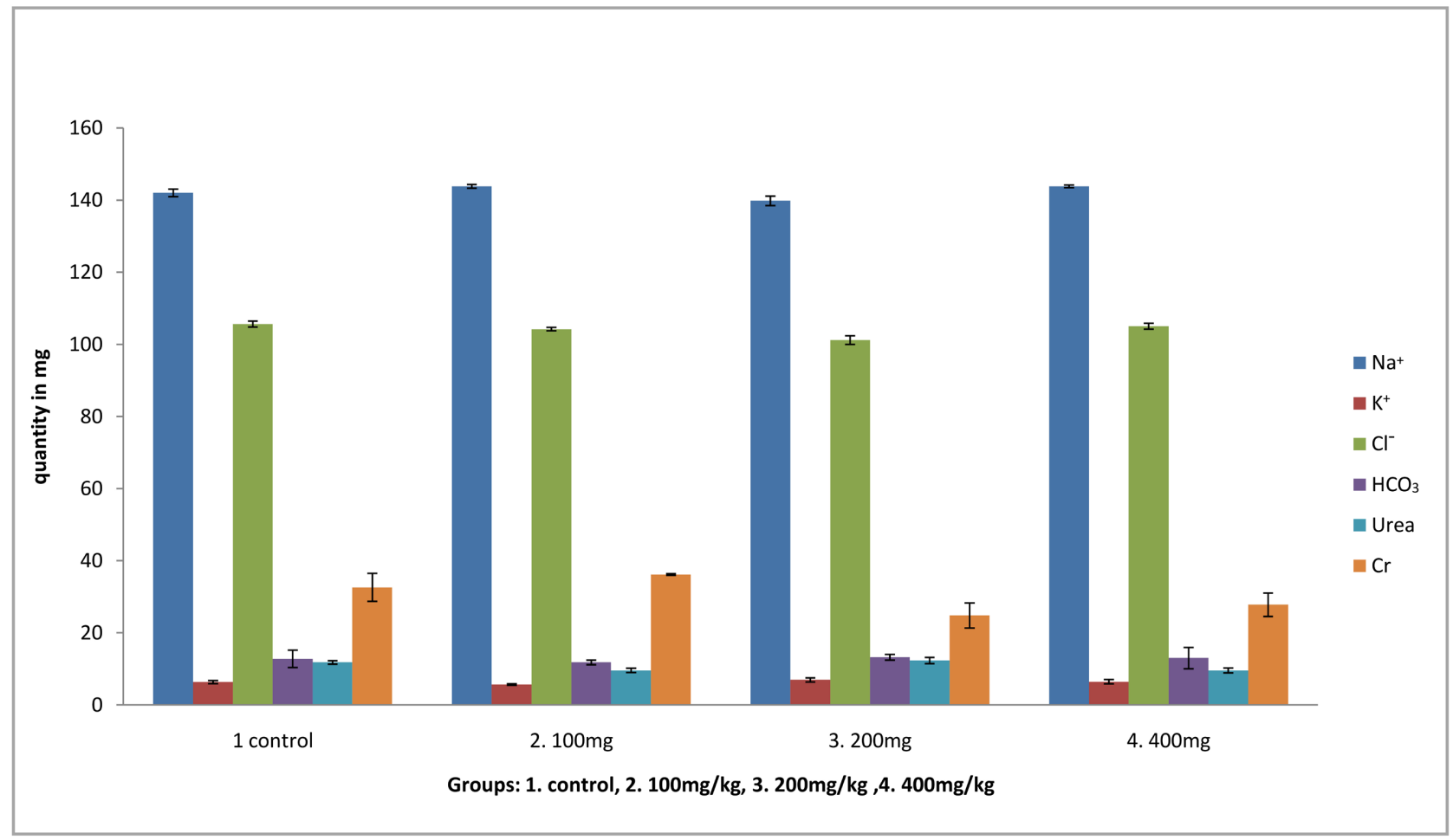

Figure 3. Effects of Stereospermum kunthianum aqueous methanolic stem bark ex-tract on renal (electrolyte, urea and creatinine) indices. 


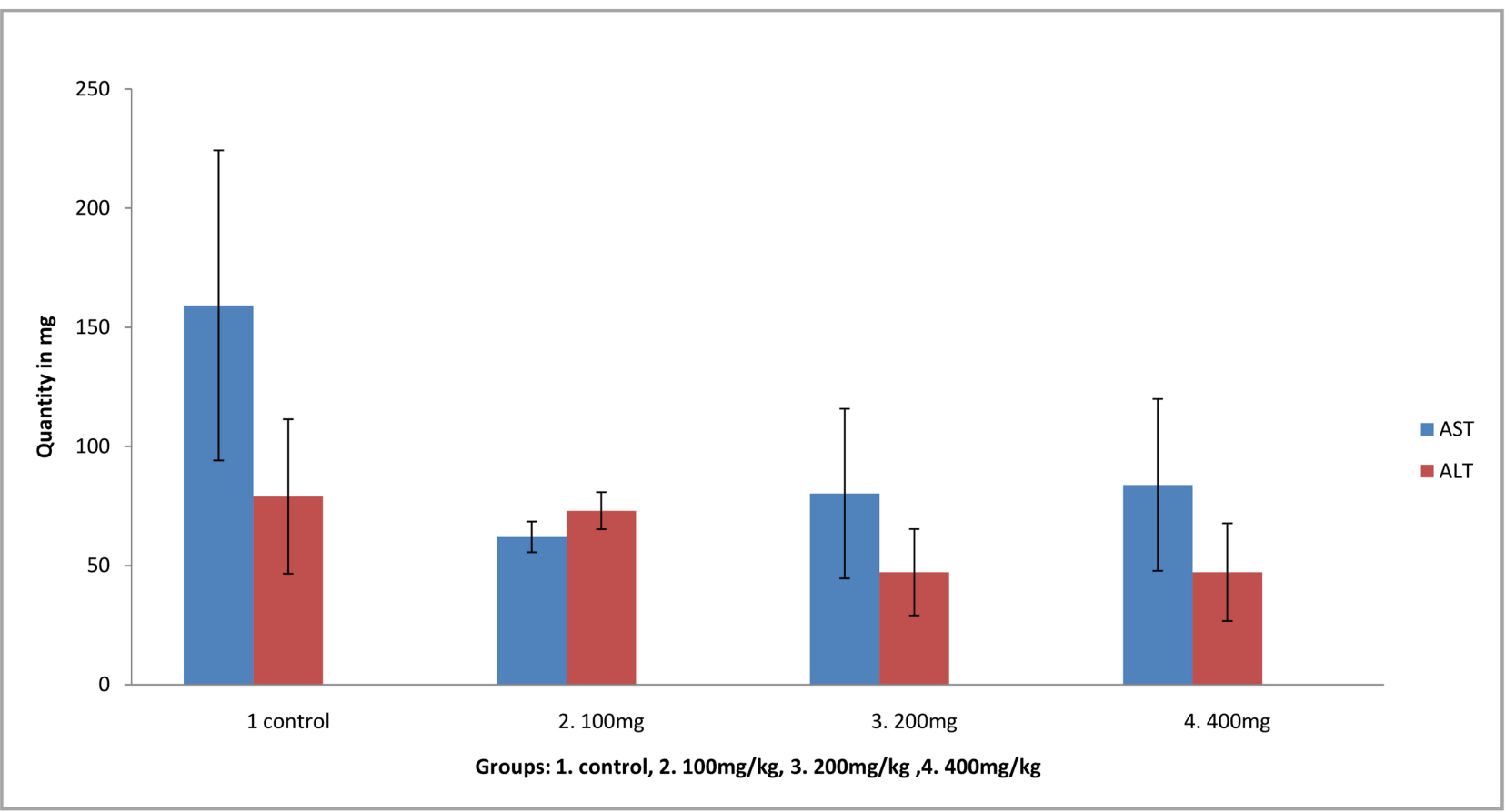

Figure 4. Effects of Stereospermum kunthianum aqueous methanolic stem bark extract on two hepatic parameters.

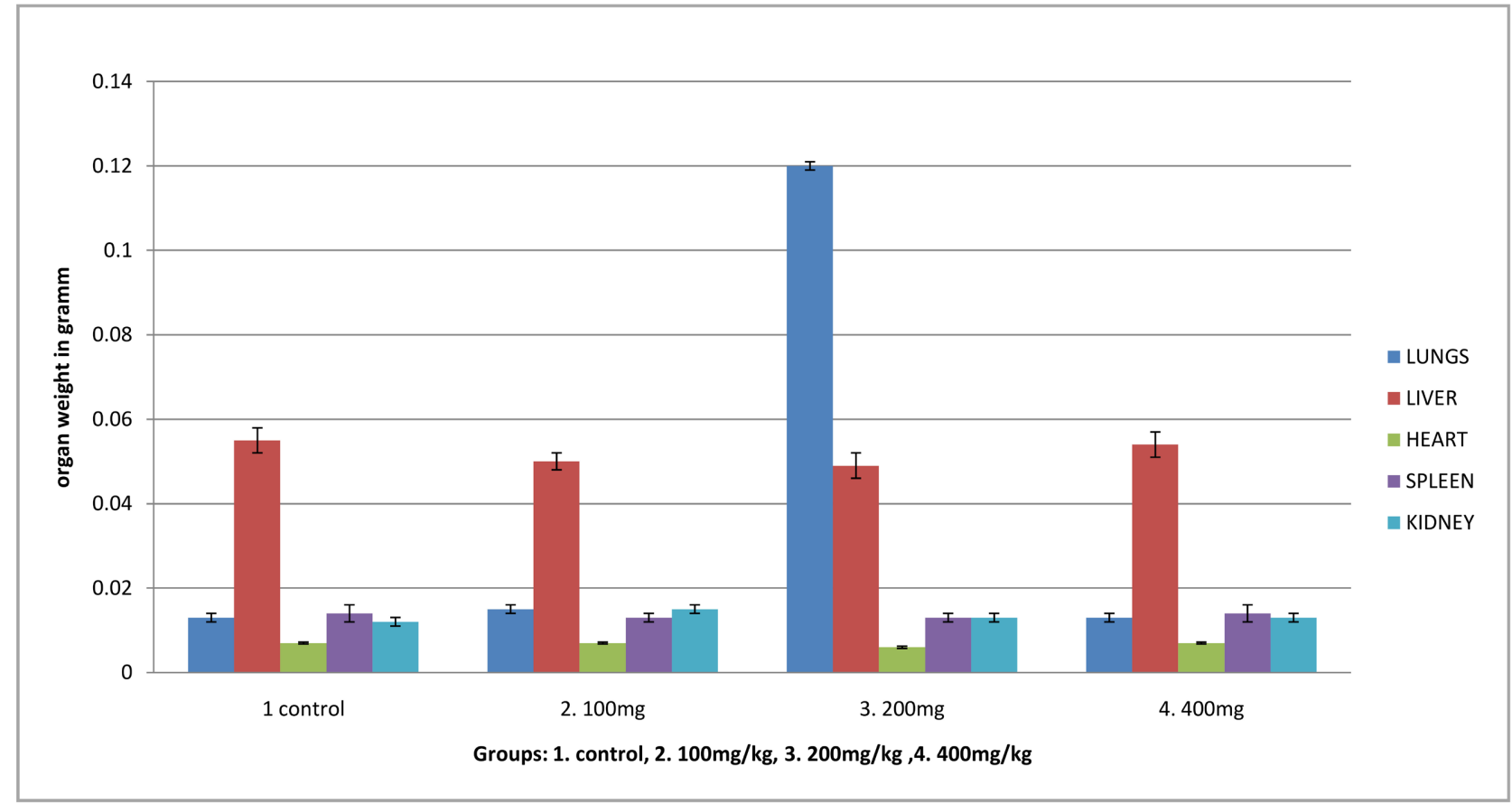

Figure 5. Effects of Stereospermum kunthianum aqueous methanolic stem bark ex-tract on organ weights of rats.

\subsection{Histopathological Report}

Lungs: There were thickened alveoli septa with mononuclear cellular infiltration and pulmonary haemorrhage indicative of interstitial pneumonia seen only in the treatment groups (Stereospermum kunthianum aqueous methanolic stem bark extract). Photomicrograph $1 \& 2$. 
Liver: The presence of hepatic necrosis with mononuclear cellular infiltration indicative of hepatitis in all the Stereospermum kunthianum aqueous methanolic stem bark extract exposed groups compared to the control. Photomicrograph $3,4 \& 5$

Heart: No visible histopathological changes occurred within the heart of the treated Wistar rats compared to the control indicating no effect. Photomicrograph $6 \mathrm{a} \& 6 \mathrm{~d}$.

Spleen: Showed diffuse lymphocytic hyperplasia in all the Stereospermum kunthianum aqueous methanolic stem bark extract treated groups compared to the control indicative of reactive follicular hyperplasia in response to either endogenous or exogenous insults.

Photomicrograph $7 \& 8$

Kidney: The kidneys of the exposed groups showed tubular necrosis with interstitial haemorrhage and mononuclear cellular infiltration indicating interstitial nephritis.

Photomicrograph $9 \& 10$

Photomicrograph $1 \mathrm{H} \& \mathrm{E}$ : Photomicrograph of the lung of a control Wistar rat exposed to distilled water only. Note the alveolus (A) with unicellular septum (arrows).

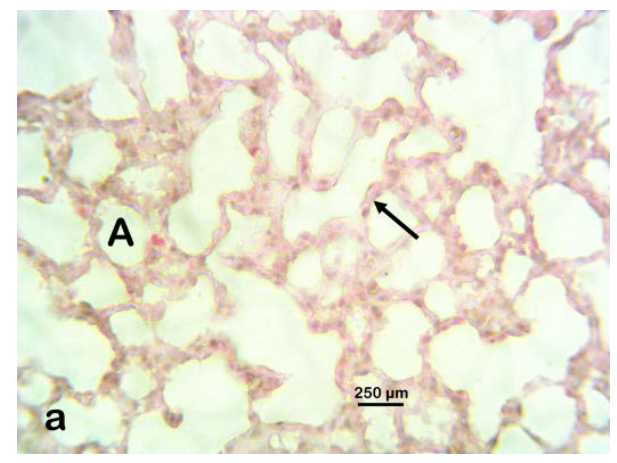

\section{Photomicrograph 1}

Photomicrograph $2 \mathrm{H} \& \mathrm{E}$ : Photomicrograph of the lung of a Wistar rat exposed to the Stereospermum kunthianum aqueous methano lic stem bark extract at $200 \mathrm{mg} / \mathrm{kg}$ for 28 days. Note the thickened alveoli septa with mononuclear cellular infiltration (X) and pulmonary haemorrhage (arrows).

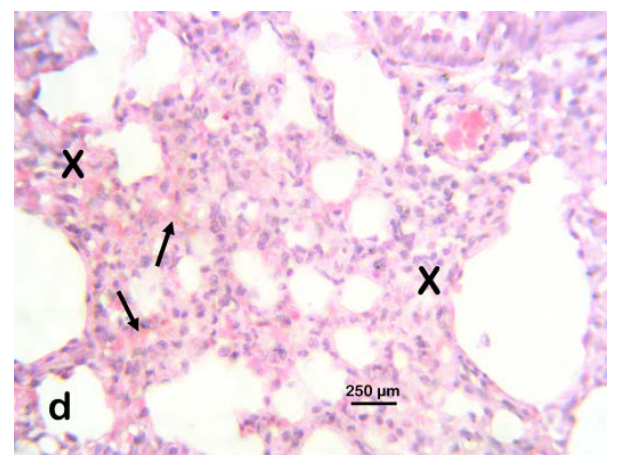




\section{Photomicrograph 2}

Photomicrograph $3 \mathrm{H} \& \mathrm{E}$ : Photomicrograph of the liver of a control Wistar rat treated with distilled water. Note the portal triad (X) and the hepatic cord (arrow).

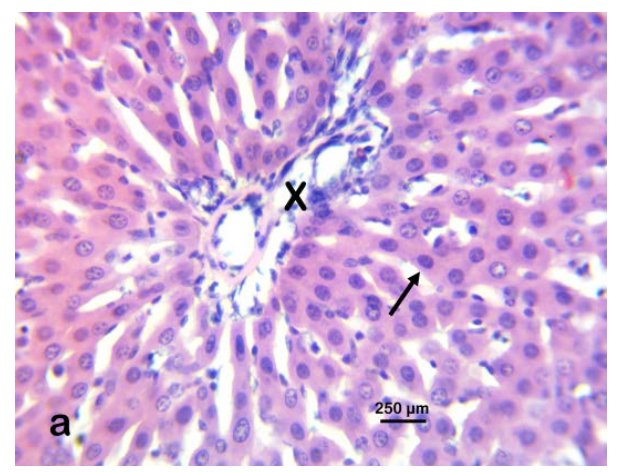

\section{Photomicrograph 3}

Photomicrograph $4 \mathrm{H} \& \mathrm{E}$ : Photomicrograph of the liver of a Wistar rat treated with $100 \mathrm{mg} / \mathrm{kg}$ Stereospermum kunthianum aqueous methanolic stem bark extract for 28 days. Note the hepatic necrosis (X) with mononuclear cellular infiltration (arrows).

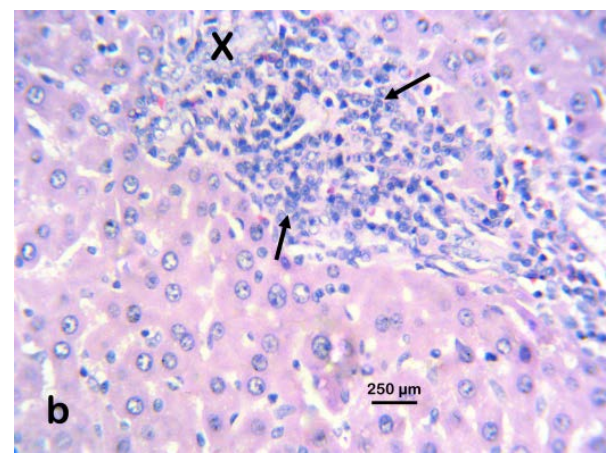

\section{Photomicrograph 4}

Photomicrograph $5 \mathrm{H}$ \& E: Photomicrograph of the liver of a Wistar rat treated with $400 \mathrm{mg} / \mathrm{kg}$ of Stereospermum kunthianum aque ous methanolic stem bark extract for 28 days. Note the hepatic necrosis (X) with mononuclear cellular infiltration (arrows).

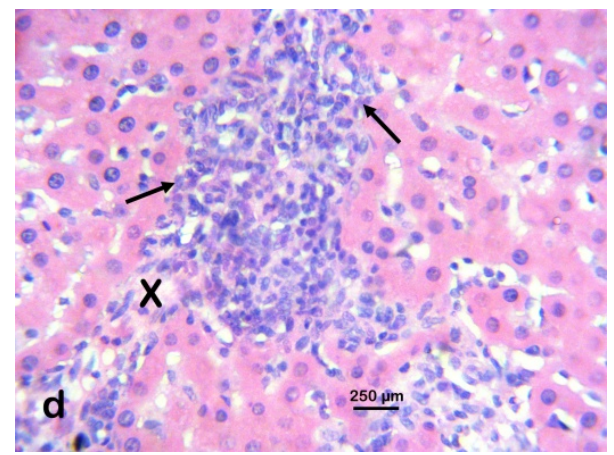




\section{Photomicrograph 5}

Photomicrograph 6a \& 6d H \& E: Photomicrograph of the heart of a Wistar rat treated with $400 \mathrm{mg} / \mathrm{kg}$ of Stereospermum kunthianum aqueous methanolic stem bark extract for 28 days. Note the cardiomyocyte (X) and a branching cardiomyocyte (arrow) same as the control.
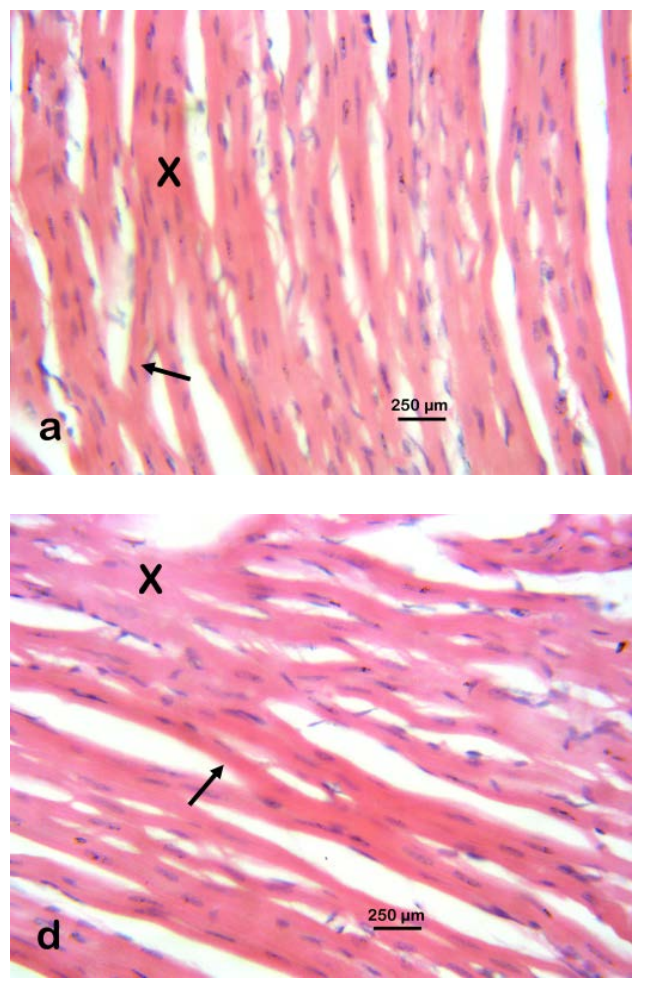

Photomicrograph 6(a) control; Photomicrograph 6(d) 400 mg/kg group

Photomicrograph $7 \mathrm{H} \& \mathrm{E}$ : Photomicrograph of the spleen of a control Wistar rat treated with distilled water for 28 days. Note the germinal follicle $(w)$ and the red pulp (R).

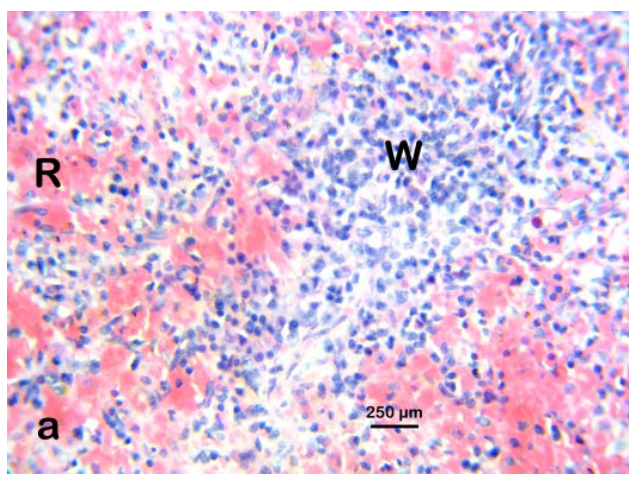

\section{Photomicrograph 7}

Photomicrograph $8 \mathrm{H} \&$ E: Photomicrograph of the spleen of a Wistar rat treated with $400 \mathrm{mg} / \mathrm{kg}$ Stereospermum kunthianum aqueous methanolic stem bark extract for 28 days. Note the diffuse lymphocytic hyperplasia (X). 


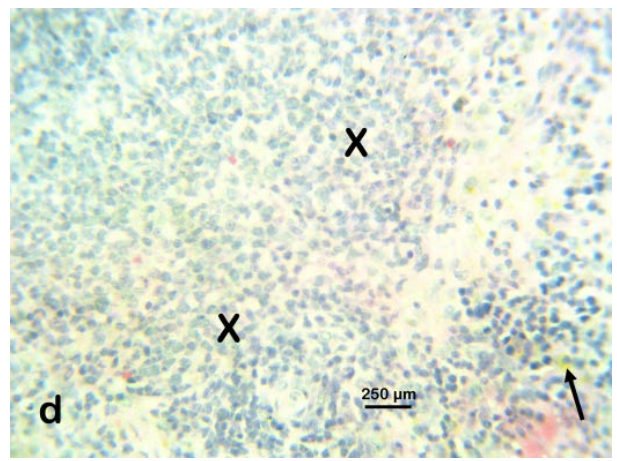

\section{Photomicrograph 8}

Photomicrograph $9 \mathrm{H}$ \& E: Photomicrograph of the kidney of a control Wistar rat treated with distilled water for 28 days. Note the glomerulus (G), distal convoluted tubule (D), and proximal convoluted tubule (P).

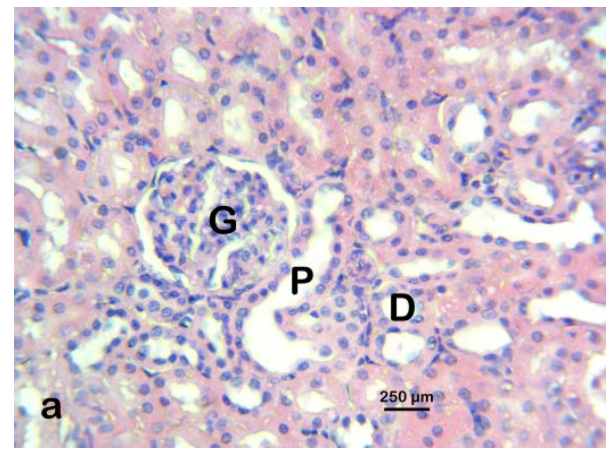

\section{Photomicrograph 9}

Photomicrograph $10 \mathrm{H} \& \mathrm{E}$ : Photomicrograph of the kidney of a Wistar rat treated with $400 \mathrm{mg} / \mathrm{kg}$ Stereospermum kunthianum aque ous methanolic stem bark extract for 28 days. Note the interstitial haemorrhage (X) also seen in other treatment groups $(100,200 \mathrm{mg} / \mathrm{kg})$.

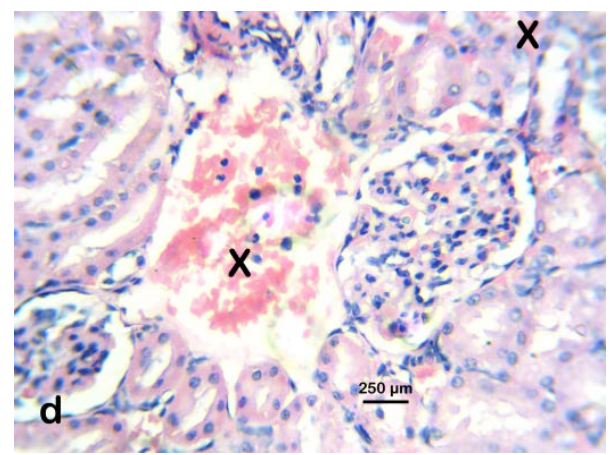

\section{Photomicrograph 10.}

\section{Discussion}

The adverse effects and mortality reported (no deaths, no observable clinical signs of toxicity, no obvious stress or changes in physical appearance or behav- 
ioural changes observed in the rats) in this study within the groups over the 28 days study period is in agreement with the earlier finding of the LD 50 reported as $5000 \mathrm{mg} / \mathrm{kg}$ for Stereospermum kunthianum aqueous methanolic stem bark [7] and this is an acceptable value recognised as a safe level for compounds being tested after acute exposure [13]. Also in concordance of the safety of the plant is that the number of death recorded in experimental animals is an indicator of the administered compound's toxicity [14] which was zero in this research work. This general picture of safety of Stereospermum kunthianum aqueous methanolic stem bark is further supported by the Turkey's multiple comparison post hoc test of the organs weights, the renal parameters (electrolyte, urea and creatinine), the haematological parameters (RBC, HB, PCV, MCV, MCH, MCHC, and Platelet), and the hepatic enzymes (AST and ALT), that all showed the control group to be insignificantly different from the extract treated groups. Further buttressing the safety of the extract is the histological reports of the heart that was alike for both the treatment groups and the control, indicative of no pathological damage to the organ. Several plant extracts are reported safe for treatment of several illnesses [15] which has informed several Asian and African nations, including Nigeria, to encourage traditional medicine as an integral component of their public healthcare programme [16] [17] with licenses and approval easily achieved by these products.

The pathological presentation as in these reports; lungs-interstitial pneumonia (Photomicrograph 2), liver-hepatitis (Photomicrograph 5), spleen-reactive follicular hyperplasia (Photomicrograph 8) and kidney-interstitial nephritis (Photomicrograph 10), are indicative of response to either endogenous or exogenous insults that arguably could be as a result of an infective process probably acquired during the experimental period or from either contamination [18] of the extract or attributed to the administrative technique (hygiene procedure adhered to in between dosing of the animals), as are often reported [18].

In fact, the effects of Stereospermum kunthianum aqueous methanolic stem bark extract on two hepatic parameters (Figure 4) examined, AST and ALT rather showed the enzyme value raised in the control and dropping in the extract treatment groups, though this was not statistically significant, it could be a sign of the extract being hepatoprotective [19]. An expectation on seeing the report of hepatitis would have been the reverse of the enzyme value as presented in this study, being that AST and ALT resides in the hepatocytes and are released following the damage to the liver cells [20]. Another point is that the renal electrolyte urea and creatinine value of the control, as well did not have a significant statistically difference relative to the treatment groups (Figure 3), even in the light of the histopathological report (interstitial nephritis) that would have in concordance showed raised and deranged values of these parameter [21]. These points, further supports the notion that it is rather an acquired infective scenario than the direct offence of the extract phytochemicals on the different organs, though the possibility cannot be totally excluded [22]. 
Following the general conclusion of the extract's relative safety in toxicity profile sense, it suffices to look at the parameters yet to be explained as seen in the study. The water (Figure 2) and feed (Figure 1) intake ANOVA between groups and within groups for each week $(1-4)$ of the experiment indicated significant $(\mathrm{p} \leq 0.000)$ differences in the intake water and the intake feeds on the $1^{\text {st }}(\mathrm{p} \leq$ $0.021)$ and $4^{\text {th }}(\mathrm{p} \leq 0.009)$ weeks respectively. The picture obvious was there was high intake water only in the first week of the research after which there were no noticeable differences in the water intake in the subsequent weeks. This increase in the water intake did not drop [21] the sodium level in the final week nor was the potassium raised [21] neither was there a biocarbonate derangement as expected in renal pathology [21] not to mention the creatinine and urea values. It also means that the extract intake was not toxic enough to cause alteration in the feed intake or cause renal organ damage.

\section{Conclusion}

In conclusion, the extract studied, Stereospermum kunthianum aqueous methanolic stem bark, in this experiment ( 28 days study period) was deduced to be safe on oral administration due to the fact that there were no deaths, no observable clinical signs of toxicity and the safe findings of both gross and laboratory investigations as stated herein. Also deduced was the probability of the plant having a hepatoprotective quality.

\section{Ethics Approval}

Ethical approval was gotten from the University of Abuja Research Ethics Committee on animal use (assigned number UAECAU/2018/002) and the internationally accepted principles for laboratory animal use and care as contained in the Canadian Council on Animal Care Guidelines were adhered to.

\section{Acknowledgements}

The authors appreciate the technical staff and animal holding unit of the National Institute for Pharmaceutical Research and Development (NIPRD) Abuja, Nigeria for their support.

\section{Availability of Data and Materials}

All data related to this manuscript are presented within the text.

\section{Funding}

Institutional based TETFUND (Tertiary Education Trust Fund) with approval number FUND/DESS/UNI/ABUJA/RP/VOL.1.

\section{Conflicts of Interest}

The authors declare no conflicts of interest regarding the publication of this paper. 


\section{References}

[1] Gill, L.S. (1992) Ethnomedicinal Uses of Plants in Nigeria. University of Benin Press, Benin City.

[2] Keay, R.W.J., Onochie, C.F.A. and Standfield, D.P. (1989) Trees of Nigeria. Clarendon, London.

[3] Igoli, J.O., Ogaji, O.G., Tor-Anyiin, T.A. and Igoli, N.P. (2005) Traditional Medicine Practice amongst the Igede People of Nigeria. Part II. African Journal of Traditional, Complementary and Alternative Medicines, 2, 134-152. https://doi.org/10.4314/ajtcam.v2i2.31112

[4] Useful Tropical Plants. https://tropical.theferns.info/viewtropical.php?id=Stereospermum+kunthianum

[5] Von Maydell, H. (1990) Trees and Shrubs of the Sahel, Their Characteristics and Uses. Deutsche Gesellschaft fur Technische Zusammenarbeit, Dag-HammarskjöldWeg.

[6] Ching, F.P., Omogbai, E. and Otokiti, I. (2009) Extract of Stereospermum kunthianum (Cham, Sandrine Petit) Protects against Generalized Seizures in Pentylenetetrazole and Electro-Convulsive Model in Rodents. African Journal of Traditional, Complementary and Alternative Medicine, 6, 544-548.

https://doi.org/10.4314/ajtcam.v6i4.57197

[7] Okwoche, O.J., Nwinyi, F.C., Egua, M.O., et al. (in press) Evaluation of Hypoglycaemic Activity in Rats and in Vitro Antioxidant Effects of the Aqueous Methanol Extract of Stereospermum kunthianum (Cham, Sandrine Petit) Stem Bark.

[8] Zimmermann, M. (1983) Ethical Guidelines for Investigations of Experimental Pain in Conscious Animals. Pain, 16, 109-110. https://doi.org/10.1016/0304-3959(83)90201-4

[9] Organization for Economic Co-Operation and Development (OECD) (2008) Test No. 407: Repeated Dose 28-Day Oral Toxicity Study in Rodents. OECD Publishing, Paris.

[10] Etuk, E.O., Igbokwe, V., Ajagbonna, O.P. and Egua, M.O. (2009) Toxicological Studies of a Nigerian Commercial Polyherbal Product in Albino Rats. Research Journal of Medicinal Plants, 3, 52-60. https://www.academicjournals.com https://doi.org/10.3923/rjmp.2009.52.60

[11] Nashwan, A.A., Aied, M.A., Marina, M.B. and Anand, R. (2018) Acute and SubAcute Oral Toxicity of Dracaena cinnabari Resin Methanol Extract in Rats. BMC Complementary and Alternative Medicine, 18, 50. https://doi.org/10.1186/s12906-018-2110-3

[12] (1996) Teco Diagnostics Kit Method. Teco Diagnostics 1268 N. Lakeview Ava Anaheim, Ca 92807 U.S.A.

[13] OECD/OCDE 420 (2001) OECD Guideline for Testing of Chemicals. Acute Oral Toxicity-Fixed Dose Procedure. https://www.oecd.org/chemicalsafety/risk-assessment/1948378.pdf

[14] Shankar, T.N., Santha, N.V., Ramesh, H.P., Murthy, I.A. and Murthy, V.S. (1980) Toxicity Studies on Turmeric (Curcuma longa): Acute Toxicity Studies in Rats, Guinea Pigs and Monkeys. The Indian Journal of Experimental Biology, 18, 73-75.

[15] Susana, O.M., Tonny, A.-A., Mary-Ann, A., Peter, A.J., Daniel, B., Doris, K., Alfred, A., Augustine, O., Yaw, D.B. and Christian, A. (2019) Medicinal Plants for Treatment of Prevalent Diseases. In: Pharmacognosy_Medicinal Plants, IntechOpen, London. 
[16] Ajagbonna, O.P. and Onyeyilli, P.A. (2002) Effects of Ethanolic Extract of Rhaptopeta lum corioceum Oliv (Scytopetalaceae) Stem Bark on Mean Anterial Pressure and Heart Rate in Rats in Nigeria. Journal of Experimental Biology, 2, 17-21.

[17] Kudi, A.C. and Myint, S.H. (1999) Antiviral Activity of Some Nigeria Medicinal Plant Extracts. Journal of Enthnopharmacology, 68, 289-294.

https://doi.org/10.1016/S0378-8741(99)00049-5

[18] Kosalec, I., Cvek, J. and Tomić, S. (2009) Contaminants of Medicinal Herbs and Herbal Products. Archives of Industrial Hygiene and Toxicology, 60, 485-501. https://doi.org/10.2478/10004-1254-60-2009-2005

[19] Mohamed, S.T.S., Madhusudhana, C.C., et al. (2010) Hepatoprotective Herbs-A Review. International Journal of Research in Pharmaceutical Sciences, 1, 1-5.

[20] Jenna, E.B. and Misty, A.E. (2021) Diseases of the Gastrointestinal System. In: Pugh, D.G., Baird, A.N., Edmondson, M.A. and Passler, T., Eds., Sheep, Goat, and Cervid Medicine, Third Edition, Elsevier, Amsterdam, 63-96. https://doi.org/10.1016/B978-0-323-62463-3.00014-1

[21] Risch, L. and Hess, B. (2013) Pitfalls bei Laborwerten-Elektrolyte, Harnstoff und Kreatinin [Pitfalls in the Interpretation of Laboratory Parameters-Electrolytes, Urea, Creatinine]. Therapeutische Umschau, 70, 457-464. https://doi.org/10.1024/0040-5930/a000432

[22] Leonard, S., Felix, S. and Victor, J.N. (2013) Chapter 35. Hepatotoxicity of Herbals and Dietary Supplements. In: Kaplowitz, N. and DeLeve, L.D., Eds., Drug-Induced Liver Disease, Third Edition, Academic Press, Cambridge, 631-657. https://doi.org/10.1016/B978-0-12-387817-5.00035-2 